\title{
The Place of Fluvoxamine in the Treatment of Non-critically ill Patients with COVID-19: A Living Systematic Review and Meta-analysis
}

Salah Eddine Oussama Kacimi ${ }^{1,2^{*+}}$, Elona Greca ${ }^{1,3+}$, Mohamed Amine Haireche ${ }^{4}$, Ahmed Sallam ElHawary ${ }^{5}$, Mounir Ould Setti ${ }^{6}$, Rebecca Caruana ${ }^{7}$, Sahar Rizwan ${ }^{8}$, Hidayet Benyettou ${ }^{1,9}$, Mohammad Yasir Essar ${ }^{10}$, Jaffer Shah ${ }^{11,12} \&$ Sherief Ghozy ${ }^{13}$ (1)

\section{${ }^{1}$ Division of Research and Academic Affairs, Larkin Community Hospital, South Miami, USA}

${ }^{2}$ Faculty of Medicine, University of Tlemcen, Tlemcen, Algeria

${ }^{3}$ University of Medicine, Tirana, Albania

${ }^{4}$ Building 6822, Waly al Ahd, Holy Makkah 4024-24353, KSA

${ }^{5}$ Qena Faculty of Medicine, South Valley University, Qena, Egypt.

${ }^{6}$ Institute of Public Health and Clinical Nutrition, University of Eastern Finland, Kuopio,

Finland

${ }^{7}$ Faculty of Medicine and Surgery, University of Malta, Malta

${ }^{8}$ Jinnah Sindh Medical University, Karachi, Pakistan

${ }^{9}$ Department of Cardiology, University-Hospital Center of Tlemcen, Tlemcen, Algeria

${ }^{10}$ Kabul University of Medical Sciences, Kanya, Afghanistan

${ }^{11}$ Medical Research Center, Kateb University, Kabul, Afghanistan

12 Drexel University College of Medicine, Philadelphia, PA, US

${ }^{13}$ Department of Radiology, Mayo Clinic, Rochester, MN, US

${ }^{+}$Co-first authors

* Correspondence

Corresponding authors: Salah Eddine Oussama Kacimi; Faculty of Medicine, University of Tlemcen, Tlemcen 13000, Algeria; Kacimi.oussama97@yahoo.com; +213 557106895. 


\section{Abstract}

Background: Fluvoxamine is a selective serotonin reuptake inhibitor that is known to be used as antidepressant. Repurposing of Fluvoxamine for the treatment of COVID-19 is theorized to help in the prevention of the clinical deterioration of SARS CoV-2 patients. In our systematic review and meta-analysis, we aim to assess the safety and efficacy of the drug under study in terms of its effect on the mortality and the risk of hospitalization and mechanical ventilation in non-critically ill COVID-19 patients.

Methods: We performed a systematic search of seven electronic databases. The search results were screened based on the previously determined inclusion and exclusion criteria. We determined the data related to our objectives. The mortality rates, rates of hospitalization, risk of mechanical ventilation and serious side effects were extracted from the studies that successfully met our inclusion and exclusion criteria. Then, the extracted data from the included studies was included in the meta-analysis.

Results: Three studies, two randomized clinical trials and one observational cohort study, with 1762 patients, were the final outcome of our search and screening processes. Among all participants, 886 patients received Fluvoxamine while 876 were controls. Follow up periods ranged from 7 days to 28 days. There was no significant difference in the intention-to-treat mortality rates between the two groups $\left(\mathrm{RR}=0.66 ; 95 \% \mathrm{CI}: 0.36-1.21, \mathrm{p}\right.$-value $=0.18 ; I^{2}=$ $0 \%$ ). However, Fluvoxamine decreased the per-protocol mortality compared to both placebo alone or placebo/standard care $\left(\mathrm{RR}=0.09 ; 95 \% \mathrm{CI}\right.$ : $0.01-0.64$, $\mathrm{p}$-value $=0.02 ; I^{2}=0 \%$ and $\mathrm{RR}$ $=0.09 ; 95 \% \mathrm{CI}: 0.01-0.72$, respectively). As compared to placebo or standard care, the allcause hospitalization was significantly reduced in the fluvoxamine group $(\mathrm{RR}=0.71 ; 95 \% \mathrm{CI}$ : $0.54-0.93, \mathrm{p}$-value $\left.=0.01 ; I^{2}=61 \%\right)$. This risk reduction was not significant when compared to placebo alone $\left(\mathrm{RR}=0.76 ; 95 \% \mathrm{CI}\right.$ : $0.57-1.00 ; \mathrm{p}$-value $\left.=0.051 ; I^{2}=48 \%\right)$. Furthermore, the risk of mechanical ventilation was not improved in the fluvoxamine group as compared to placebo $\left(\mathrm{RR}=0.71 ; 95 \% \mathrm{CI}: 0.43-1.16, \mathrm{p}\right.$-value $\left.=0.17 ; I^{2}=0 \%\right)$. The serious adverse effects were almost the same in the treatment group and the control (13\% and $12 \%$ respectively).

Conclusion: Fluvoxamine does not significantly reduce the mortality rates or the risk of mechanical ventilation in SARS CoV-2 patients. Nonetheless, it was found to have a good impact on reducing all cause hospitalization among patients with COVID-19 disease. Therefore, further clinical studies are needed to determine the effectiveness of the drug and its mechanisms of action. 


\section{Introduction}

Coronavirus disease 2019 (COVID-19) is a pandemic that has emerged in the city of Wuhan, China, at the end of 2019 and has spread with highly transmissibility all over the globe in $2020^{[1],[2],[3]}$. Symptoms severity, according to the largest cohort of more than 44,000 persons infected with COVID-19 from China, can range from mild (81\%), severe (14\%) to critical (5\%) $[4],[5]$. During the critical phase, patients may rapidly deteriorate one week after coronavirus disease onset, which increases the urge to discover drugs that prevents this condition ${ }^{[6],[7]}$.

In November 2020, a randomized clinical trial, reported by Dr. Lenze and his colleagues assessed the efficacy of Fluvoxamine (FLV) in adult patients with COVID-19 for prevention of clinical deterioration ${ }^{[8]}$. FLV is a selective serotonin reuptake inhibitor (SSRI), mainly used to treat obsessive-compulsive disorder, but also major depressive disorder and anxiety disorders ${ }^{[9]}$. It has not been FDA-approved for the treatment of any infection since April 2021 when it was added to the US National Institutes of Health (NIH) COVID-19 Guidelines Panel ${ }^{[10]}$.

Potential mechanisms of action of FLV for COVID-19 are the immune modulation aspect and antiviral effect ${ }^{[11,12,13]}$. There are four factors that might play a key role in immune modulation. First, the activity of the sigma 1 receptor that could be leading to inositol-requiring enzyme 1alpha - driven (IRE1). Second, the decreased activity of platelet aggregation. Third, decreased activity of mast cells. Fourth, increased level of melatonin by cytochrome P450 inhibition. All of them play a significant role in decreasing inflammation during COVID-19 $9^{[11,12,14]}$. On the other hand, the anti-viral effect of FLV is focused on the interference with viral entry and endolysosomal viral trafficking ${ }^{[11]}$.

We aimed to carry out a systematic literature review and meta-analysis of all published RCTs and prospective cohort studies to evaluate the safety and efficacy of Fluvoxamine in noncritically ill patients with confirmed COVID-19 diagnosis, with the goal of helping to clarify the possibility of repurposing of this drug. 


\section{Methods}

\section{Data Source}

We followed the PRISMA (Preferred Reporting Items for Systematic reviews and MetaAnalyses) checklist for reporting systematic reviews and meta-analyses ${ }^{[15]}$. One investigator systematically searched Medline, Google Scholar, Scopus, Opengrey, Clinicaltiral.gov, Cochrane, and MedRxiv from database inception till November $1^{\text {st }}, 2021$ to retrieve studies in humans of the efficacy and safety of Fluvoxamine in the treatment of non-critically ill patients with confirmed COVID-19 diagnosis. The following keywords were used for the retrieval of relevant studies: "Fluvoxamine", "COVID", "COVID-19", and "Coronavirus". Additionally, the reference list of the included studies was scrutinized to retrieve further studies. Finally, we included all original studies with no publication date or language restrictions to not miss any relevant papers.

\section{Study Selection}

Studies were considered relevant if 1) their aim was to assess the efficacy and/or safety of Fluvoxamine in the treatment of non-severe cases of COVID-19 2) they are double-arm studies 3) patients in these studies diagnosed with COVID-19 or its symptomatology is not severe enough to require hospitalization at baseline 4) reported enough data to be used in the metaanalysis. Therefore, we included both observational studies (cohort studies) and clinical trials. Studies conducted among ICU-admitted patients were not considered in this meta-analysis. If a specific dataset has been published more than once, we used the most recent publication. Preprints without peer-reviewed publication were also included. We excluded studies that were not reported as full reports such as conference abstracts and letters unless they provide enough data. Secondary studies including systematic reviews, narrative reviews, and computational studies were excluded from this systematic review. Studies performed on animal models were also excluded.

\section{Data Extraction \& Quality Assessment}

The following data were extracted by two independent reviewers from each article: country, study design, number of participants in both Fluvoxamine and control arms, Fluvoxamine dose, and drug-intake duration, duration of the follow-up, percentage of participants lost in follow-up, and description of the reported primary outcomes. Additionally, demographic data of studies' participants were also extracted. Separately, the outcomes reported in the studies including intention-to-treat mortality, per-protocol mortality, mechanical ventilation, hospitalization, presence of serious adverse events (SAE), and presence of any adverse events (AE) were extracted as raw data (event and total) and not as effect estimates. Grade 3, 4, and 5 adverse 
included studies was assessed by two other independent reviewers using the NIH Quality Assessment Tool for Controlled Intervention Studies and Cohort Studies ${ }^{[17]}$.

\section{Data Synthesis \& Analysis}

The primary endpoint was to assess the effect of Fluvoxamine on the risk of mortality, mechanical ventilation, or hospitalization among COVID-19 patients without severe illness at baseline. In the first part, we gathered raw data represented by the number of event occurrences among total patients in each arm from both observational and interventional studies. Thereafter, we calculated pooled effect estimates and their corresponding 95\% confidence intervals (CI) from these raw data. At the second time, only interventional studies comparing Fluvoxamine with placebo were considered in separate meta-analyses. Because of the prospective nature of all the included studies, Relative Risk (RR) was used as an effect estimate.

All data were analyzed by means of the "meta" package; R software version 4.0.2. We computed the pooled RRs and their corresponding 95\% CI using the fixed effects model. Heterogeneity of the effect across studies was assessed by $\mathrm{Q}^{2}$ statistics, which is distributed as $X^{2}$ statistics ${ }^{[18]}$. A value of $\mathrm{p}$-value $<0.05$ was used to indicate a lack of homogeneity (heterogeneity) among effects. $I^{2}$ statistics were provided to quantify the percentage of total variation across studies that was attributable to heterogeneity rather than to chance. We used a fixed-effects model if the $I^{2} \mathrm{p}$ value significance was $<0.05$. Otherwise, a random-effects model was used. Due to the small number of the included studies ( $<10$ per the analysis), neither subgroup analysis, Egger's 


\section{Results}

\section{Inclusion flowchart}

Two independent reviewers screened the title and abstracts of 155 potentially relevant nonduplicate studies. Of the 155 abstracts, a total of 96 abstracts was excluded due to the reasons mentioned in the PRISMA flow diagram (Figure 01). Consequently, full texts of 11 studies were assessed for eligibility of which 8 were excluded ( 7 studies did not meet the first eligibility criteria and 1 study was reported among patients admitted to the ICU ${ }^{[21]}$. Additionally, no studies were identified through hand-searching of the reference list of the included studies. Finally, three studies ( 2 interventional and 1 observational) met the eligibility criteria and were included in the review and meta-analysis. The PRISMA flow diagram is depicted in (Figure 01)

\section{Description of the included studies}

All included studies were published in English. Among the three studies, two [16,8] were randomized double-blinded placebo-controlled trials and one ${ }^{[22]}$ was an observational cohort study. All the included studies were prospective with a maximum follow-up duration of 28 days reported in the TOGETHER study. The minimum follow-up duration was 14 days. The sample size of the included studies ranged from 133 to 1497. Two studies were conducted in the United State of America and one study in Brazil. Fluvoxamine was administered daily at different doses and durations in the included studies. Primary outcomes were heterogeneous among included studies. COVID OUT study assessed the clinical deterioration of COVID-19 patients, TOGETHER study assessed the retention in COVID-19 emergency or transfer to tertiary care, while Seftel et al. assessed mortality, ICU admission, and persistence of COVID-19 symptomatology as the primary outcome. Details of the characteristics of the included studies can be found in (Table1)

\section{Baseline characteristics of studies' participants}

All the included studies reported age, percentage of gender, ethnicity/race, and comorbidities. However, Seftel et al. failed to provide data regarding body-mass index (BMI). Additionally, Seftel et al. reported data on only three comorbidities (hypertension, diabetes, and chronic lung disease). Baseline characteristics were not different between Fluvoxamine arm and control arm among the included studies except for gender that was not well-matched in Seftel et al. with 59\% of males in Fluvoxamine arm and $41 \%$ in standard care arm. Diabetes, hypertension, and lung disease are the most prevalent comorbidities among participants. Full demographic data can be found in (Table2)

\section{Outcomes}


241 Fluvoxamine did not reduce risk of mortality from COVID-19 RR $=0.66$ (95\% CI: $0.36-1.21$,

TOGETHER study, Fluvoxamine has significant reduction in per protocol mortality as compared to the placebo or standard care (SC) $\mathrm{RR}=0.09$ (95\% CI: $0.01-0.64$, p-value $=0.02 ; I^{2}=0 \%$ ).

As compared to placebo or SC, Fluvoxamine showed benefit on reducing risk for all-cause hospitalization RR $=0.71\left(95 \%\right.$ CI: $0.54-0.93$, p-value $\left.=0.01 ; I^{2}=61 \%\right)$, but did not for the risk of mechanical ventilation (MV) $\mathrm{RR}=0.71\left(95 \% \mathrm{CI}: 0.43-1.16\right.$, p-value $\left.=0.17 ; I^{2}=0 \%\right)$. Forest plots can be found on the (Supplementary).

\section{Fluvoxamine compared to a placebo alone}

When compared to placebo alone, Fluvoxamine did no reduce the risk of intention-to-treat death $\mathrm{RR}=0.69(95 \%$ CI: $0.38-1.27$, p-value $=0.24)$, but showed a benefit on per protocol death $\mathrm{RR}$ $=0.09(95 \%$ CI: $0.01-0.72$, p-value $=0.02)$. When compared to placebo alone, Fluvoxamine did not reduce the risk for both $\mathrm{MV}$ and hospitalization $\mathrm{RR}=0.76\left(0.46-1.24\right.$, $\mathrm{p}$-value $=0.27 ; I^{2}=$ $0 \%)$ and $\mathrm{RR}=0.76\left(0.57-1.00, \mathrm{p}\right.$-value $\left.=0.051 ; I^{2}=48 \%\right)$, respectively. Incidence of serious adverse events was not different among Fluvoxamine (10\%) and placebo arm (12\%) (p-value for treatment group $(13 \%)$ and placebo group $(12 \%) \mathrm{RR}=1.06\left(0.82-1.38, \mathrm{p}\right.$-value $=0.65 ; I^{2}=$ $0 \%$ ). Details regarding outcomes can be found on (Table3)

\section{Risk of bias}

Using the NIH quality assessment tool for interventional studies, we find both RCTs to be of good quality. On the other hand, the quality of the prospective cohort study by Seftal et al. was fair using the same tool adapted for cohort studies. 


\section{Discussion}

COVID-19 disease is the disease of the era. Its high prevalence forced the Scientists to race against time to find a vaccine that prevents infection, as well as a treatment for the severe symptoms of the disease. Many theoretical experiments have suggested the repurposing of particular drugs, and accordingly, many clinical studies have been conducted to verify the effectiveness of these proposed drugs ${ }^{[23,24]}$. Some of these medicines have proven effective, whether in relieving the symptoms or even in curing the disease. Fluvoxamine was one of these drugs ${ }^{[10]}$. It is a drug for the nervous system used as an antidepressant through its action as a selective serotonin reuptake inhibitor (SSRI) ${ }^{[25]}$. The use of antidepressant drugs as antiviral agents was not of the moment. They have previously been used in the Middle East Respiratory Syndrome (MERS) and the Severe Acute Respiratory Syndrome (SARS), and some clinical and preclinical studies have proven their success in improving the condition of patients with these two diseases ${ }^{[26,27]}$.

Repurposing of fluvoxamine was theorized to be beneficial in preventing the progression of severity of SARS CoV-2 disease ${ }^{[8]}$. These theories were based on the anti-inflammatory properties of the drug which come mainly from its moderate to high affinity to sigma-1 receptors (S1R ${ }^{[28]}$. Among all antidepressants, fluvoxamine was found to have the highest potency at S1R ${ }^{[29-31]}$. S1R is an endoplasmic reticulum (ER) chaperone protein that plays a regulatory role of cytokines production in the sittings of inflammation ${ }^{[30]}$. It interferes with the ER stress (cytokine storm) syndrome which occurs accordingly to the SARS CoV-2 viral replication within the human cells and contributes to the high mortality of the disease ${ }^{[30,32-33]}$. In addition, S1R was identified by Gordon et al to play a pivotal inhibitory role in the viral RNA replication process of SARS CoV-2 ${ }^{[30,34]}$. Thus, the agonistic effect of fluvoxamine on sigma-1 receptors has supported the theories of its use as anti-inflammatory and antiviral agent in the treatment of SARS CoV-2 disease ${ }^{[29]}$. There are many other theories (e.g. inhibition of platelet aggregation, mast cell degranulation and lysosomotropism) linking the mechanisms of action of fluvoxamine and its possible efficacy in COVID-19 patients ${ }^{[11]}$.

A few clinical studies have been conducted to confirm the efficacy of fluvoxamine in alleviating the severe symptoms and preventing the progression of the disease. In our systematic review and meta-analysis, we assessed the efficacy of fluvoxamine in terms of its effects on mortality rates, risk of hospitalization and mechanical ventilation as factors that can be relied upon to determine the effectiveness of the drug in treating the disease.

Although the COVID OUT randomized clinical trial (which was performed by Lenze et al ${ }^{[8]}$ ) was not a large trial, it opened the gaze for the high need to perform larger trials to reach a reliable conclusion about the efficacy of the drug. Of all the included studies, the TOGETHER trial was the largest and the most recent trial ${ }^{[16]}$. 
The increased mortality rates among COVID 19 patients increased the demand to check for

319 drugs that may reduce the high risk of death especially in advanced age ${ }^{[35,36]}$. In their large multicenter retrospective observational cohort study, Oskotsky et al indicated the effectiveness of SSRIs, specifically fluoxetine and fluoxetine or fluvoxamine, in reducing the mortality rates among the groups that used this category of antidepressants compared to the control group ${ }^{[37]}$. In our review, we found that there was no significant difference in the ITT mortality rates between fluvoxamine group and placebo or $\mathrm{SC}(\mathrm{RR}=0.66$; 95\% CI: $0.36-1.21)$. However, the PP mortality from the TOGETHER trial indicated a real and effective difference between the two groups ( $\mathrm{RR}=0.09 ; 95 \% \mathrm{CI}: 0.01-0.64)$. Therefore, this can give the preference to the use of fluoxetine over fluvoxamine in the reduction of mortality among COVID-19 patients. We can also infer from this the superiority of fluoxetine and fluvoxamine over the other SSRIs ${ }^{[37,38]}$.

\section{Conclusion}

Repurposing of fluvoxamine in treatment of SARS CoV-2 patients has not shown significant efficacy in reducing either the mortality rates or mechanical ventilation. However, it showed promising results in reducing the risk for hospitalization among patients with COVID-19 disease. 


\section{References}

1. World Health Organization. Corona- virus disease (COVID-19) outbreak. Available at

https://www.who.int/health-topics/coronavirus. last accessed in $5^{\text {th }}$ of November 2021.

2. Lu H, Stratton CW, Tang YW. Outbreak of pneumonia of unknown etiology in wuhan China: the mystery and the miracle. J Med Virol: published online Jan 16. DOI:10.1002/jmv.25678. health - the latest 2019 novel coronavirus outbreak in Wuhan, China. Intl. J. Infect. Dis. 91, 264-

4. Liu Y, Yan L, Wan L, Xiang T, Le A, Liu J et al. Viral dynamics in mild and severe cases of COVID-19. The Lancet Infectious Diseases. 2020;20(6):656-657.

5. Zhonghua Liu Xing Bing Xue Za Zhi. Epidemiology Working Group for NCIP Epidemic characteristics of an outbreak of 2019 novel coronavirus diseases (COVID-19) in China. 2020; 41:145-151.

6. Yang X, Yu Y, Xu J, et al. Clinical course and outcomes of critically ill patients with SARSRespir Med 2020 Jan 2020 to Mar 2020: A Multi-Center, Retrospective Cohort Study in China. Front. Med., 03 December 2020 | https://doi.org/10.3389/fmed.2020.567296

8. Lenze E, Mattar C, Zorumski CF, Stevens A, Schweiger J, Nicol GE, Miller JP, Yang L,

372 Yingling M, Avidan MS, Reiersen AM. Fluvoxamine vs placebo and clinical deterioration in outpatients with symptomatic COVID-19. A randomized clinical trial. JAMA. 2020;324(22):2292-2300. doi: 10.1001/jama.2020.22760.

9. Figgitt, D.P., McClellan, K.J. Fluvoxamine. Drugs 60, 925-954 (2000). https://doi.org/10.2165/00003495-200060040-00006 Guidelines. National Institutes of Health. Available at

381 11. Sukhatme VP, Reiersen AM, Vayttaden SJ and Sukhatme VV (2021) Fluvoxamine: A

382 Review of Its Mechanism of Action and Its Role in COVID-19. Front. Pharmacol. 12:652688. 
12. Hashimoto K. Activation of sigma-1 receptor chaperone in the treatment of neuropsychiatric diseases and its clinical implication. Journal of Pharmacological Sciences. 2015;127(1):6-9.

13. Hashimoto, K. Repurposing of CNS drugs to treat COVID-19 infection: targeting the sigma-

14. DeDiego M, Nieto-Torres J, Jiménez-Guardeño J, Regla-Nava J, Álvarez E, Oliveros J et al. Severe Acute Respiratory Syndrome Coronavirus Envelope Protein Regulates Cell Stress

Response and Apoptosis. PLoS Pathogens. 2011;7(10):e1002315.

15. Moher D, Liberati A, Tetzlaff J, Altman D. Preferred Reporting Items for Systematic

Reviews and Meta-Analyses: The PRISMA Statement. PLoS Medicine. 2009;6(7):e1000097.

16. Reis G, dos Santos Moreira-Silva E, Silva D, Thabane L, Milagres A, Ferreira T et al. Effect of early treatment with fluvoxamine on risk of emergency care and hospitalisation among patients with COVID-19: the TOGETHER randomised, platform clinical trial. The Lancet Global Health. 2021;10(1):e42-e51.

17. NIH Quality Assessment Tools. https://www.nhlbi.nih.gov/health-topics/study-qualityassessment-tools last accessed in 17 December 2021.

18. Higgins JPT, Green S. Identifying and measuring heterogeneity. In: Julian PTH, Sally G, editors. Cochrane Handbook for Systematic Reviews of Interventions. Chichester: CoPublication Between The Cochrane Collaboration; (2011)

19. Egger M, Smith G, Schneider M, Minder C. Bias in meta-analysis detected by a simple,

20. Peters JL, Sutton AJ, Jones DR, Abrams KR, Rushton L. Comparison of two methods to detect publication bias in meta-analysis. JAMA. 2006 Feb 8; 295(6):676-80. efficacy of fluvoxamine in COVID-19 ICU patients: An open label, prospective cohort trial with matched controls. Br J Clin Pharmacol. 2021 Nov 1:10.1111/bcp.15126. doi: 10.1111/bcp.15126. Epub ahead of print. PMID: 34719789; PMCID: PMC8653355. 
23. Yousefi, Hassan et al. "Repurposing existing drugs for the treatment of COVID-19/SARSvol. 183 (2021): 114296. doi: 10.1016/j.bcp.2020.114296.

24. Farne, Hugo et al. "Repurposing Existing Drugs for the Treatment of COVID-19." Annals of the American Thoracic Society vol. 17,10 (2020): 1186-1194. doi:10.1513/AnnalsATS.202005$566 \mathrm{FR}$

25. Burton, S W. "A review of fluvoxamine and its uses in depression." International clinical psychopharmacology vol. 6 Suppl 3 (1991): 1-17; discussion 17-21. doi:10.1097/00004850199112003-00001.

437 Collection small molecule library identifies potential anti-coronavirus drugs." Antiviral research $438 \quad 114$ (2015): 1-10.

27. Dyall, Julie, et al. "Repurposing of clinically developed drugs for treatment of Middle East respiratory syndrome coronavirus infection." Antimicrobial agents and chemotherapy 58.8

441 (2014): 4885-4893.

28. Rosen, Dorian A et al. "Modulation of the sigma-1 receptor-IRE1 pathway is beneficial in preclinical models of inflammation and sepsis." Science translational medicine vol. 11,478

444 (2019): eaau5266. doi:10.1126/scitranslmed.aau5266.

29. Ishima, Tamaki et al. "Interaction of new antidepressants with sigma-1 receptor chaperones and their potentiation of neurite outgrowth in PC12 cells." European journal of pharmacology vol. 727 (2014): 167-73. doi: 10.1016/j.ejphar.2014.01.064. sigma-1 receptor." European archives of psychiatry and clinical neuroscience vol. 271,2 (2021): 249-258. doi:10.1007/s00406-020-01231-x. neuropsychiatric diseases and its clinical implication." Journal of pharmacological sciences vol. 127,1 (2015): 6-9. doi: 10.1016/j.jphs.2014.11.010.

33. Banerjee, Aditi et al. "Crosstalk between endoplasmic reticulum stress and anti-viral activities: A novel therapeutic target for COVID-19." Life sciences vol. 255 (2020) : 117842. Doi : 10.1016/j.lfs.2020.117842. 
461 35. Challen, Robert, et al. "Risk of mortality in patients infected with SARS-CoV-2 variant of

462 concern 202012/1: matched cohort study." bmj 372 (2021).

463 36. CDC, COVID 19 updates. https://www.cdc.gov/coronavirus/2019-ncov/covid-

464 data/investigations-discovery/hospitalization-death-by-age.html. last accessed on 12 Dec. 2021.

465 37. Oskotsky, Tomiko et al. "Mortality Risk Among Patients With COVID-19 Prescribed

466 Selective Serotonin Reuptake Inhibitor Antidepressants.” JAMA network open vol. 4,11

467 e2133090. 1 Nov. 2021, doi:10.1001/jamanetworkopen.2021.33090.

468

469

38. Hoertel, Nicolas. "Do the Selective Serotonin Reuptake Inhibitor Antidepressants Fluoxetine and Fluvoxamine Reduce Mortality Among Patients With COVID-19?” JAMA network open

Table 01: Characteristics of the included studies.

Table 02: Baseline characteristics among patients of the included studies.

Table 03: Summary of the patients' outcomes. 
medRxiv preprint doi: https://doi.org/10.1101/2021.12.19.21268044; this version posted December 21, 2021. The copyright holder for this

preprint (which was not certified by peer review) is the author/funder, who has granted medRxiv a license to display the preprint in perpetuity.

It is made available under a CC-BY-NC-ND 4.0 International license .

\begin{tabular}{|c|c|c|c|c|c|c|c|c|}
\hline \multirow[b]{2}{*}{ Study } & \multirow[b]{2}{*}{ Country } & \multirow{2}{*}{$\begin{array}{l}\text { Study } \\
\text { design }\end{array}$} & \multicolumn{2}{|c|}{ Population, N } & \multirow{2}{*}{$\begin{array}{l}\text { Fluvoxamine } \\
\text { dose/ duration }\end{array}$} & \multirow{2}{*}{$\begin{array}{l}\text { FU } \\
\text { duration }\end{array}$} & \multirow{2}{*}{$\begin{array}{l}\text { Loss } \\
\text { of FU, \% }\end{array}$} & \multirow{2}{*}{$\begin{array}{l}\text { Primary } \\
\text { outcome }\end{array}$} \\
\hline & & & Fluv & Control & & & & \\
\hline $\begin{array}{l}\text { COVID } \\
\text { OUT }\end{array}$ & USA & $\begin{array}{l}\text { Double- } \\
\text { blinded } \\
\text { Placebo- } \\
\text { controlled } \\
\text { RCT } \\
\end{array}$ & 80 & 72 & $\begin{array}{l}100 \mathrm{mg} \times 3 / 15 \\
\text { days }\end{array}$ & 15 days & $20 \%$ & $\begin{array}{l}\text { clinical } \\
\text { deterioration }\end{array}$ \\
\hline TOGETHER & Brazil & $\begin{array}{l}\text { Double- } \\
\text { blinded } \\
\text { Placebo- } \\
\text { controlled } \\
\text { RCT }\end{array}$ & 741 & 756 & $\begin{array}{l}100 \mathrm{mg} \times 2 / 10 \\
\text { days }\end{array}$ & 28 days & NA & $\begin{array}{l}\text { retention in a } \\
\text { COVID-19 } \\
\text { emergency } \\
\text { setting/transfer to } \\
\text { the tertiary } \\
\text { hospital due to } \\
\text { COVID-19 }\end{array}$ \\
\hline $\begin{array}{l}\text { Seftel et al. } \\
2021\end{array}$ & USA & $\begin{array}{l}\text { Observational } \\
\text { prospective } \\
\text { cohort } \\
\text { study }\end{array}$ & 65 & 48 & $\begin{array}{l}50 \mathrm{mg} \times 2 / 14 \\
\text { days }\end{array}$ & 14 days & $0 \%$ & $\begin{array}{l}\text { Hospitalization, } \\
\text { ICU admission } \\
\text { mortality, the } \\
\text { persistence of } \\
\text { symptoms }\end{array}$ \\
\hline
\end{tabular}

491

492

493

494

495

496

497

498

499

500

501

502

503

504

505

506 
Table 2: Baseline characteristics among patients of the included studies

\begin{tabular}{|c|c|c|c|c|c|c|}
\hline \multirow[b]{2}{*}{ Baseline Characteristics } & \multicolumn{2}{|c|}{ TOGETHER } & \multicolumn{2}{|c|}{ COVID OUT } & \multicolumn{2}{|c|}{ Seftel et al. 2021} \\
\hline & $\begin{array}{l}\text { Fluvoxamine } \\
(\mathrm{N}=741) \\
\end{array}$ & $\begin{array}{l}\text { Placebo } \\
(\mathrm{N}=756) \\
\end{array}$ & $\begin{array}{c}\text { Fluvoxamine } \\
(\mathrm{n}=\mathbf{8 0})\end{array}$ & $\begin{array}{l}\text { Placebo } \\
(\mathrm{n}=72) \\
\end{array}$ & $\begin{array}{l}\text { Fluvoxamine } \\
\quad(n=65)\end{array}$ & $\begin{array}{l}\text { Standard care } \\
\quad(n=48)\end{array}$ \\
\hline Age, Median (IQR) & $50(39-56)$ & $49(38-56)$ & $46(35-58)$ & $45(36-54)$ & $44 \pm 15^{\mathrm{a}}$ & $43 \pm 15^{\mathrm{a}}$ \\
\hline Males, $\%$ & 45 & 40 & 30 & 26 & 59 & 41 \\
\hline \multicolumn{7}{|l|}{ Race, $\%$} \\
\hline Black or African American & 1 & 1 & 23 & 28 & 1.5 & 0 \\
\hline Mixed race & 96 & 95 & - & - & - & - \\
\hline White & 1 & 1 & 70 & 69 & 5 & 27 \\
\hline Unknown & 3 & 3 & 1 & 0 & - & - \\
\hline \multicolumn{7}{|l|}{ Ethnicity, \% } \\
\hline Asian & - & - & 4 & 1 & 0 & 2 \\
\hline Latino & - & - & 4 & 3 & 94 & 71 \\
\hline \multicolumn{7}{|l|}{ Chronic comorbidity, \% } \\
\hline Anxiety & - & - & 6 & 1 & - & - \\
\hline Asthma & 2 & 2 & 21 & 13 & - & - \\
\hline Auto-immune diseases & 0 & $<1$ & - & - & - & - \\
\hline Chronic heart disease & 1 & 1 & - & - & - & - \\
\hline Chronic kidney disease & $<1$ & $<1$ & - & - & - & - \\
\hline Chronic neurological disease & 1 & 1 & - & - & - & - \\
\hline Chronic pulmonary disease & 1 & $<1$ & - & - & 3 & 2 \\
\hline Depression & - & - & 1 & 6 & - & - \\
\hline Diabetes & 17 & 15 & 11 & 11 & 17 & 8 \\
\hline Hyperlipidemia & - & - & 9 & 10 & - & - \\
\hline Hypertension & 14 & 12 & 19 & 21 & 17 & 35 \\
\hline Rheumatological disorder & $<1$ & 0 & 5 & 4 & - & - \\
\hline Any other disease & 3 & 3 & - & - & - & - \\
\hline \multicolumn{7}{|l|}{ Body-mass index, $\%$} \\
\hline$<30 \mathrm{~kg} / \mathrm{m} 2$ & 48 & 49 & 46 & 42 & - & - \\
\hline$\geq 30 \mathrm{~kg} / \mathrm{m} 2$ & 51 & 50 & 54 & 58 & - & - \\
\hline Unspecified & 1 & 1 & 0 & 0 & - & - \\
\hline
\end{tabular}




\section{Table 3: Summary of the patients' outcomes.}

\begin{tabular}{|c|c|c|c|c|c|c|}
\hline \multirow{2}{*}{ Outcome } & \multirow[b]{2}{*}{$\begin{array}{l}\text { No. } \\
\text { studies }\end{array}$} & \multirow{2}{*}{$\begin{array}{l}\text { Fluvoxamine } \\
\text { Event/total } \\
(\%)\end{array}$} & \multirow{2}{*}{$\begin{array}{l}\text { Control arm } \\
\text { Event/total } \\
(\%) \\
\end{array}$} & \multicolumn{2}{|l|}{ Fixed-effect model } & \multirow{2}{*}{$\begin{array}{l}\text { Heterogeneity } \\
\text { I', }^{2} \text { P-value }\end{array}$} \\
\hline & & & & $\operatorname{RR}(95 \% \mathrm{CI})$ & $\begin{array}{l}\text { Test for } \\
\text { overall effect, } \\
\text { P-value }\end{array}$ & \\
\hline \multicolumn{7}{|c|}{ Fluvoxamine Vs. Control arm: Placebo or standard care (observation) } \\
\hline Death, intention to treat & 3 & $2 \%$ & $3 \%$ & $0.66(0.36-1.21)$ & $\mathrm{p}=0.18$ & $0 \%, p=0.53$ \\
\hline Death, per protocol & 3 & $0.1 \%$ & $2 \%$ & $0.09(0.01-0.64)$ & $p=0.02 *$ & $0 \%, p=0.62$ \\
\hline Mechanical ventilation & 3 & $3 \%$ & $4 \%$ & $0.71(0.43-1.16)$ & $\mathrm{p}=0.17$ & $0 \%, p=0.49$ \\
\hline Hospitalization & 3 & $8 \%$ & $12 \%$ & $0.71(0.54-0.93)$ & $p=0.01 *$ & $61 \%, p=0.08$ \\
\hline
\end{tabular}

\section{Fluvoxamine Vs. Control arm: Placebo only}

\begin{tabular}{|c|c|c|c|c|c|c|}
\hline Death, intention to treat & 2 & $2 \%$ & $3 \%$ & $0.69(0.38-1.27)$ & $\mathrm{p}=0.24$ & NA \\
\hline Death, per protocol & 2 & $0.1 \%$ & $2 \%$ & $0.09(0.01-0.72)$ & $\mathbf{p}=0.02 *$ & NA \\
\hline Mechanical ventilation & 2 & $3 \%$ & $4 \%$ & $0.76(0.46-1.24)$ & $\mathrm{p}=0.27$ & $0 \%, p=0.56$ \\
\hline Hospitalization & 2 & $9 \%$ & $12 \%$ & $0.76(0.57-1.00)$ & $\mathrm{p}=0.051$ & $48 \%, p=0.17$ \\
\hline Serious adverse events ${ }^{+}$ & 2 & $10 \%$ & $12 \%$ & $0.78(0.59-1.04)$ & $\mathrm{p}=0.09$ & $48 \%, p=0.17$ \\
\hline Any other adverse events & 2 & $13 \%$ & $12 \%$ & $1.06(0.82-1.38)$ & $\mathrm{p}=0.65$ & $0 \%, p=0.34$ \\
\hline
\end{tabular}

Abbreviations: RR: Relative Risk; *, statistical significance; +, grade (3, 4, and 5) adverse events were considered as serious. 
538 Figure 01:
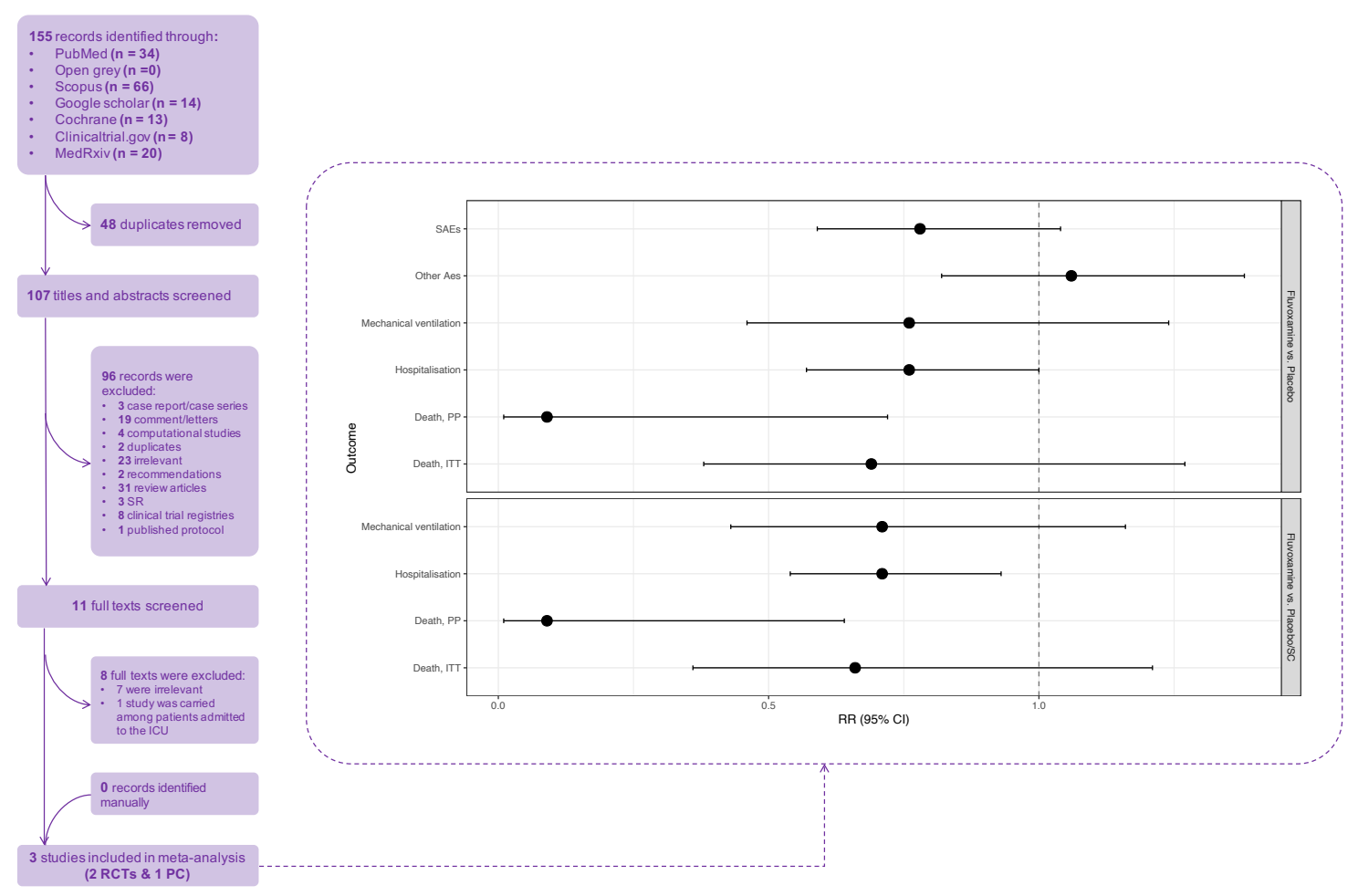